\title{
A PRESSURE-SINTERING MODEL FOR THE DENSIFICATION OF POLAR FIRN AND GLACIER ICE
}

\author{
By D.S. WILKINSON \\ (Department of Materials Science and Engineering, McMaster University, \\ Hamilton, Ontario L8S 4L7, Canada)
}

\begin{abstract}
A comprehensive multi-mechanism theory of pressure sintering has been applied to the densification of two polar ice sheets. The comparison, which is made using pressure-sintering mechanism maps, indicates that power-law creep is the controlling mechanism between $50 \%$ and $98 \%$ theoretical density. Lattice diffusion becomes dominant at low porosities. The densification rates predicted by the theory are in good agreement with the data, and suggest that a reasonable estimation of the densification behaviour of a polar ice sheet can be made using the theory, based on information obtained from a relatively shallow core.

\section{INTRODUCTION}

Metallic and ceramic components are often fabricated by the application of pressure to a powder compact at elevated temperature. This process is known as sintering (or hot pressing) and has been studied extensively. Several distinct mechanisms can contribute to the process, even when no external pressure is applied (see Table I). With the addition of an applied pressure, new mechanisms appear and some existing ones are enhanced. The pressure may cause particle fragmentation and re-arrangement (James, 1972); it may induce plasticity (including plastic creep) in the particles (Wilkinson and Ashby, 1975); and it may augment
\end{abstract}

the effect of surface energy as a driving force for diffusion (Coble, 1970).

The same mechanisms operate when snow, deposited on the surface of a glacier or ice sheet, is densified and transforms from firn to ice. In polar ice sheets (i.e. ones which do not undergo surface melting in summer), densification is entirely by solid-state processes, and is nearly identical to the solid-state pressure sintering of metals and other ceramics.

In this paper, the predictions of pressure-sintering theory will be presented for pure ice. They will then be compared with measurements from ice sheets in Greenland (Site 2) and Antarctica (Byrd Station). The possibilities for using the theory to predict the densification behaviour at other sites will also be discussed.

\section{PRESSURE-SINTERING MODELS AND THEIR APPLIC- ABILITY TO GLACIERS}

Over the past 10 years a comprehensive, geometrical theory of pressure sintering has been developed (Wilkinson and Ashby, 1978; Swinkels and others, 1983; Wilkinson, unpublished). Equations describing the rate of densification have been developed for all of the mechanisms listed in

TABLE I. POSSIBLE MECHANISMS OF PRESSURE SINTERING

\begin{tabular}{|c|c|c|c|c|c|}
\hline \multirow[t]{2}{*}{$\begin{array}{c}\text { Mechanism } \\
\text { number }\end{array}$} & \multirow[t]{2}{*}{ Mechanism } & \multicolumn{2}{|c|}{$\begin{array}{l}\text { Transport path } \\
\text { for matter }\end{array}$} & \multirow[t]{2}{*}{$\begin{array}{l}\text { Densifying } \\
\text { mechanisms }\end{array}$} & \multirow[t]{2}{*}{$\begin{array}{l}\text { Stages } \\
\text { operative }\end{array}$} \\
\hline & & From & To & & \\
\hline 0 & Elastic adhesion & & & $\mathrm{x}$ & 0 \\
\hline 1 & Plastic yielding & $\begin{array}{l}\text { Neck } \\
\text { region }\end{array}$ & $\begin{array}{l}\text { Porosity } \\
\text { surface }\end{array}$ & $\mathrm{x}$ & $1-3$ \\
\hline 2 & Power-law creep & $\begin{array}{l}\text { Neck } \\
\text { region }\end{array}$ & $\begin{array}{l}\text { Porosity } \\
\text { surface }\end{array}$ & $\mathrm{x}$ & $1-3$ \\
\hline 3 & Boundary diffusion & $\begin{array}{l}\text { Grain } \\
\text { boundary } \\
\text { in neck }\end{array}$ & $\begin{array}{l}\text { Porosity } \\
\text { surface }\end{array}$ & $\mathrm{x}$ & $1-3$ \\
\hline 4 & Lattice diffusion & $\begin{array}{l}\text { Grain } \\
\text { boundary } \\
\text { in neck }\end{array}$ & $\begin{array}{l}\text { Porosity } \\
\text { surface }\end{array}$ & $\mathrm{x}$ & $1-3$ \\
\hline 5 & Surface diffusion & Surface & $\begin{array}{l}\text { Porosity } \\
\text { surface }\end{array}$ & & \\
\hline 6 & Lattice diffusion & Surface & $\begin{array}{l}\text { Porosity } \\
\text { surface }\end{array}$ & & \\
\hline 7 & $\begin{array}{l}\text { Evaporation- } \\
\text { condensation }\end{array}$ & Surface & $\begin{array}{l}\text { Porosity } \\
\text { surface }\end{array}$ & & \\
\hline
\end{tabular}


Table I. In general, it is not possible to describe the densification process due to a given mechanism by a single equation. This is because of the radical changes in internal geometry which accompany densification. Therefore, the process is conventionally modelled as occurring in stages. During the initial stage, individual particles are still distinguishable and large curvature gradients exist in the compact. During the final stage, the particles are no longer distinguishable. Instead, models focus on the remaining pores, which are isolated and spherical. In some treatments, such as the one adopted here, an intermediate stage is also modelled. Here, the porosity is still interconnected, and the particles are still distinguishable. However, large surfacecurvature gradients no longer exist.

This picture is altered somewhat for the densification of polar firn because of the very low initial density. When metal or ceramic powders are processed, hot pressing is usually preceded by a cold pressing step, thus raising the starting density to at least $60 \%$ of theoretical and of ten higher. Clearly, this does not occur when snow is deposited on the surface of a glacier, and the initial density is of order $40 \%$. At these very low densities a range of new mechanisms involving particle re-arrangement is possible. Anderson and Benson (1963) have suggested that re-arrangement of unbonded grains is important at low density. However, because of the high vapour pressure of ice, sintering occurs rapidly and bonding between ice particles develops at low density. An alternative model proposed by Alley (1987) assumes that grain-boundary sliding controls the rate at which ice particles can pass by each other.

The morphology changes occurring during densification of polar firn are clearly visible in Figure 1, in which sections of ice taken from a polar ice sheet over a range of

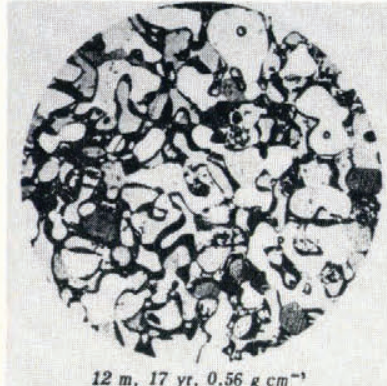

$12 \mathrm{~m}, 17 \mathrm{yt}, 0.56 \mathrm{~g} \mathrm{~cm}^{-1}$

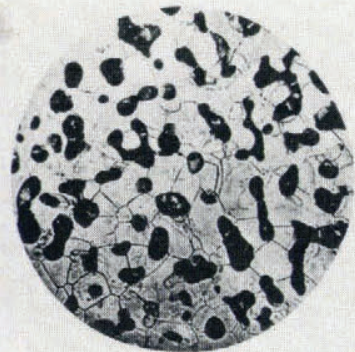

Depth $65 \mathrm{~m}$, age $118 \mathrm{yr}$, density $0.82 \mathrm{~g} \mathrm{~cm}^{-1}$

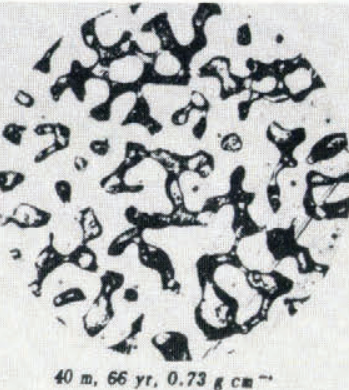

$40 \mathrm{~m}, 66 \mathrm{yt}, 0.73 \mathrm{~cm}-$

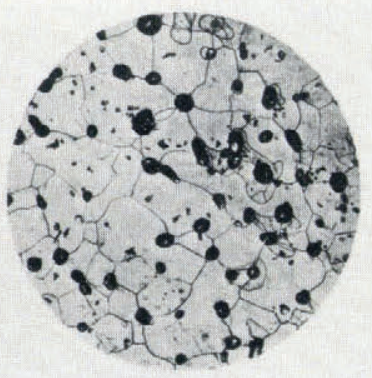

$80 \mathrm{~m}, 152 \mathrm{yr}, 0.86 \mathrm{~g} \mathrm{~cm}^{-1}$
Fig. 1. The structure of ice in the polar ice sheet at Camp Century, Greenland, as a function of depth and density (from Gow, 1975).

depths are illustrated (Gow, 1968). These pictures are similar to those observed in metals and ceramic powder compacts sintered in the absence of an external pressure. A somewhat different compact morphology emerges when metals are densified under an applied pressure. For example, Figure 2 shows the structure of a tin compact after pressure sintering to $88 \%$ theoretical density (Swinkels and others, 1983). Here the porosity is sharp or cusp-shaped. The difference between the morphologies illustrated in these two figures is important. In the former case, the surfacecurvature gradients have been continuously reduced due to surface diffusion or (as is the case with ice) by vapour transport. In the latter case, no surface re-arrangement has

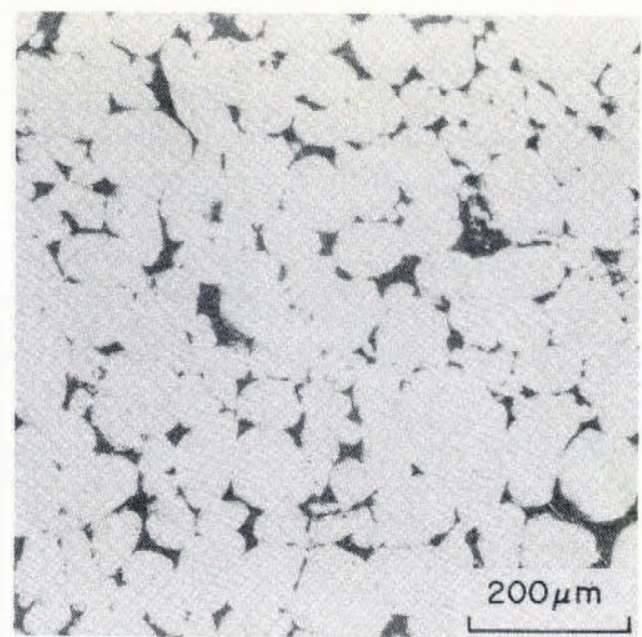

Fig. 2. The structure of tin after hot isostatic pressing for $24 \mathrm{~h}$ at $250^{\circ} \mathrm{C}$ and a pressure of $2.07 \mathrm{MPa}$. The density is $88 \%$ of theoretical. This should be compared with the structure of firn at $65 \mathrm{~m}$ depth (Fig. 1) for which the relative density is $89 \%$.

taken place. Instead, particles have only deformed plastically to conform to the pore space.

It is important that the correct morphology be used in modelling pressure sintering. Otherwise, a good correlation with experimental results is unlikely. Therefore, two sets of models, each with a different set of geometrical assumptions, have been developed. The earliest models (Wilkinson and Ashby 1978; Wilkinson, unpublished) assumed that local transport mechanisms are available to provide a smooth curvature gradient in the necks between particles. They are applicable at low applied pressures and high homologous temperature. A later set of models (Swinkels and others, 1983) assumed that no re-arrangement takes place in the neck. They are applicable at high pressures and low homologous temperatures. Because the ice in polar firn is at about $95 \%$ of its melting temperature and the pressures are moderate in the upper part of the ice sheet where most densification takes place, and because of the observed morphology as illustrated in Figure 1, the earlier models were used here.

\section{PRESSURE-SINTERING MECHANISMS MAPS FOR ICE}

Once a full set of mechanism-rate equations has been developed, one needs a convenient way of illustrating which mechanism controls densification in a material under a given set of conditions. One way of doing this is to construct pressure sintering mechanisms maps (Wilkinson and Ashby, 1978; Wilkinson, unpublished). These illustrate, in densitytemperature-applied pressure space, the regime over which a particular mechanism dominates the densification behaviour. Generally, two-dimensional diagrams are produced with relative density as the ordinate, and either pressure or temperature as the abscissa.

A pressure-sintering mechanism map for pure ice is shown in Figure 3. It is constructed using the material data listed in Table II. It applies to a constant temperature of $-27^{\circ} \mathrm{C}$, which is $0.9 T_{\mathrm{Mo}}, T_{\mathrm{Mo}}$ being the melting temperature of ice at 1 atmosphere pressure. The map is also constructed assuming particles of $0.5 \mathrm{~mm}$ radius, consistent with the firn particle size in glacier ice. The axes are the externally applied pressure normalized by the room-temperature shear modulus $\left(p_{\mathrm{e}} / \mu_{0}\right)$, and the relative density $\rho$. Calculations begin at $50 \%$ density (i.e. $0.46 \mathrm{Mg} / \mathrm{m}^{3}$ ), and assume that the initial stage of sintering is already complete for reasons that will become clear later. The map indicates that, for low applied pressure, lattice diffusion dominates the sintering rate, but as the pressure rises, power-law (or dislocation) creep (Wilkinson and Ashby, 1975) becomes the controlling mechanism. At high external pressures, plastic flow becomes very rapid and the material is best regarded as having a yield stress. Contours 


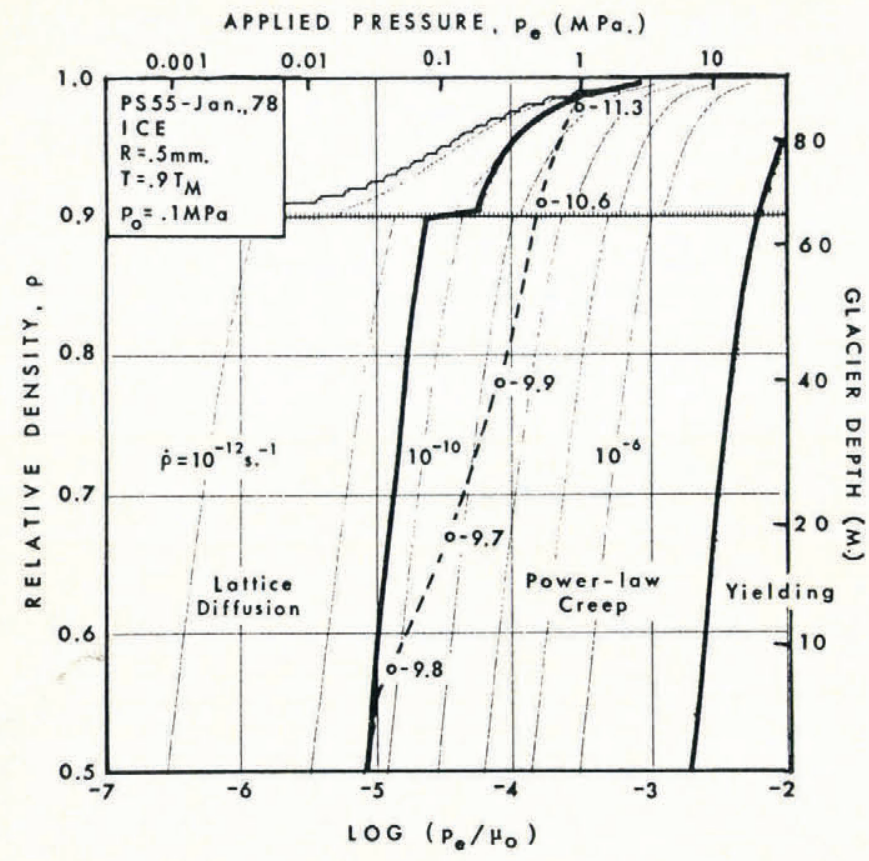

Fig. 3. A constant temperature $\left(T=0.9 T_{\mathrm{M}}\right)$ pressuresintering mechanism map for a pure ice compact of $0.5 \mathrm{~mm}$ radius particles. The axes are normalized applied pressure (log scale) and relative density. The dotted line indicates the densification profile of two polar ice sheets and lies well within the power-law creep field until $98 \%$ density.

of constant relative densification rate are also shown on the map. They are calculated by summing the densification rate due to each mechanism in an appropriate way. These predict that at, say, an applied pressure of $1 \mathrm{MPa}$, the densification rate at $80 \%$ density is $10^{-7} \mathrm{~s}^{-1}$. In producing the map it has been assumed that the porosity becomes isolated and the final stage of sintering commences at a relative density $\rho_{3}$, which we set at $90 \%$ (consistent with both polar firn (Gow, 1968) and metal powder (Coleman and Beere, 1975) compact measurements). As the relative density, $\rho$, increases, the gas pressure in the closed pores also increases.

If we assume that the number of pores per unit volume $N_{\mathrm{v}}$ remains constant, then once the porosity is closed

$$
p^{\prime}{ }_{\mathrm{i}}(1-\rho)=p^{\prime}{ }_{\mathrm{i}} N_{\mathrm{v}} \cdot V=\text { constant }
$$

where $p^{\prime}{ }_{i}$ is the gas pressure in the voids, whose average volume is $V$. Since $p^{\prime}{ }_{\mathrm{i}}$ is equal to the atmospheric pressure $p_{0}$ when $\rho=\rho_{3}$, this equation can be solved for $p_{i}^{\prime}$ at any density greater than $\rho_{3}$, yielding

$$
p_{i}^{\prime}=p_{0} \frac{1-\rho_{3}}{1-\rho} .
$$

In determining the driving pressure for sintering, however, it is the difference in gas pressure between the pores and the atmosphere which is important. This is given by

$$
p_{\mathrm{i}}=p_{0}\left[\frac{1-\rho_{3}}{1-\rho}-1\right) \text {. }
$$

Thus, the driving force for sintering $p=p_{\mathrm{e}}-p_{\mathrm{i}}+2 \gamma_{\mathrm{S}} / r$ drops with increasing density $\left(\gamma_{S}\right.$ is the surface free energy and $r$ is the average pore radius). This effect shows up on the maps as a rapid decrease in densification rate above a density of $90 \%$, especially at low applied pressure. In fact, the densification rate goes to zero when $p=0$, i.e. when

$$
p_{\mathrm{e}}=p_{0}\left[\frac{1-\rho_{3}}{1-\rho}-1\right]-\frac{2 \gamma_{\mathrm{S}}}{r} \text {. }
$$

Deep cores have been drilled to depths of several

\section{TABLE II. DATA USED TO CONSTRUCT THE MAP}

Atomic volume $\left(\mathrm{m}^{3}\right)$

Burger's vector $(\mathrm{m})$

Melting temperature (K)

Shear modulus at $300 \mathrm{~K}, \mu_{0}(\mathrm{MPa})$

Temperature coefficient of $\mu, T_{\mathbf{M}} / \mu_{0}$

Theoretical density $\left(\mathrm{kg} \mathrm{m}^{-3}\right)$

Surface energy $\left(\mathrm{J} \mathrm{m}^{-2}\right)$

Lattice-diffusion coefficient $\left(\mathrm{m}^{2} \mathrm{~s}^{-1}\right)$

Boundary-diffusion coefficient $\left(\mathrm{m}^{3} \mathrm{~s}^{-1}\right)$

Power-law creep constant $\left(\mathrm{m}^{2} \mathrm{~s}^{-1}\right)$

Power-law creep exponent

Activation energy for power-law creep $\left(\mathrm{kJ} \mathrm{mol}^{-1}\right)$

Yield stress $(\mathrm{MPa})$

(a) Dantl (1968), using $\mu=\left[\frac{1}{2} C_{44}\left(C_{11}-C_{11}\right)\right]^{1 / 2}$.

(b) At $-27^{\circ} \mathrm{C}$.

(c) Fletcher, 1970

(d) Ramseier, 1967.

(e) Estimates using $\delta D_{\mathrm{OB}}=2 b D_{\mathrm{OV}}$, and $Q_{\mathrm{b}}=2 / 3 Q_{\mathrm{V}}$.

(f) Barnes and others, 1971

(g) $R=8.314 \mathrm{~J} \mathrm{~mol}^{-1} \mathrm{~K}^{-1}$.
$3.27 \times 10^{-29}$

$4.52 \times 10^{-10}$

273

$2.98 \times 10^{-3(a)}$

$0.19^{(\mathrm{a})}$

$917^{(b)}$

$0.1^{(\mathrm{c})}$

$10^{-3} \times \exp (-59400 / R T)^{(\mathrm{d}, \mathrm{g})}$

$10^{-12} \times \exp (-39300 / R T)^{(\mathrm{e}, \mathrm{g})}$

$5.75 \times 10^{-2}(\mathrm{f})$

$3.0^{(\mathrm{f})}$

$78.7^{(\mathrm{f})}$ 
hundred metres at both Byrd Station in Antarctica (Gow, 1968) and at Site 2 in Greenland (Langway, 1967). The temperature, density, grain-size, and age of the ice have been measured as a function of depth below the surface at each site. The snow pressure and the rate of snow accumulation can also be inferred from the data. The grain-size varies only slowly with depth, increasing from about $R=0.3 \mathrm{~mm}$ near the surface to about $R=1 \mathrm{~mm}$ at $100 \mathrm{~m}$ depth, and $1.3 \mathrm{~mm}$ at several hundred metres depth ( $R$ being the grain radius). The porosity remains substantially connected to the grain boundaries during the first $100 \mathrm{~m}$ at least, although subsequent grain growth isolates some pores within grains. The data for density, temperature, pressure, and age for Site 2 are summarized in Figure 4. It shows that the temperature oscillates seasonally over the first $15 \mathrm{~m}$ in depth, but is constant and stable
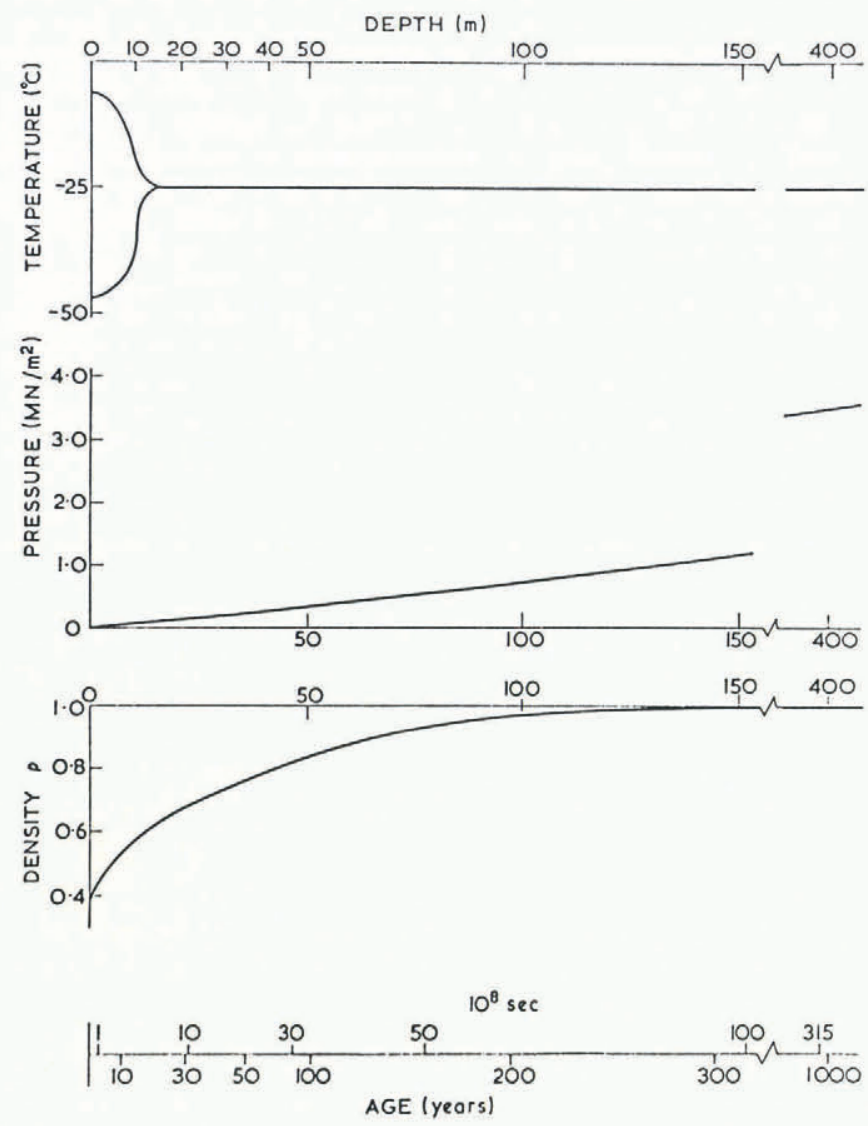

Fig. 4. A deep core, drilled at Site 2, Greenland (Langway, 1967). to a depth of $411 \mathrm{~m}$, yields data on the temperature, density, and age of the ice, from which can be inferred both the snow pressure and densification rate.

below that. The pressure, due to the snow burden, increases almost linearly with depth. Using the age as the time axis (and assuming the glacier is at steady state, i.e. the time for the snow to reach a given depth is approximately constant), the densification rate can also be obtained as a function of depth.

The temperature fluctuations in the top $15 \mathrm{~m}$ make it difficult to model this region theoretically. Furthermore, significant densification occurs at this stage by particle rearrangement due to grain-boundary sliding (Alley and Koci, 1988). By $15 \mathrm{~m}$ in depth, the largest surface-curvature gradients have been removed, and the firn fits the description of an intermediate-stage sintering compact (roughly cylindrical connected porosity), as illustrated in Figure 1. We thus begin our analysis at this point.

The data are plotted in Figure 5 on the same normalized scales of density and applied pressure used for the maps, with the densification rates presented as $\log _{10}$. The profiles for the two ice sheets vary only slightly.

Returning to the mechanism map (Fig. 3), we see the experimental data superimposed on the predicted

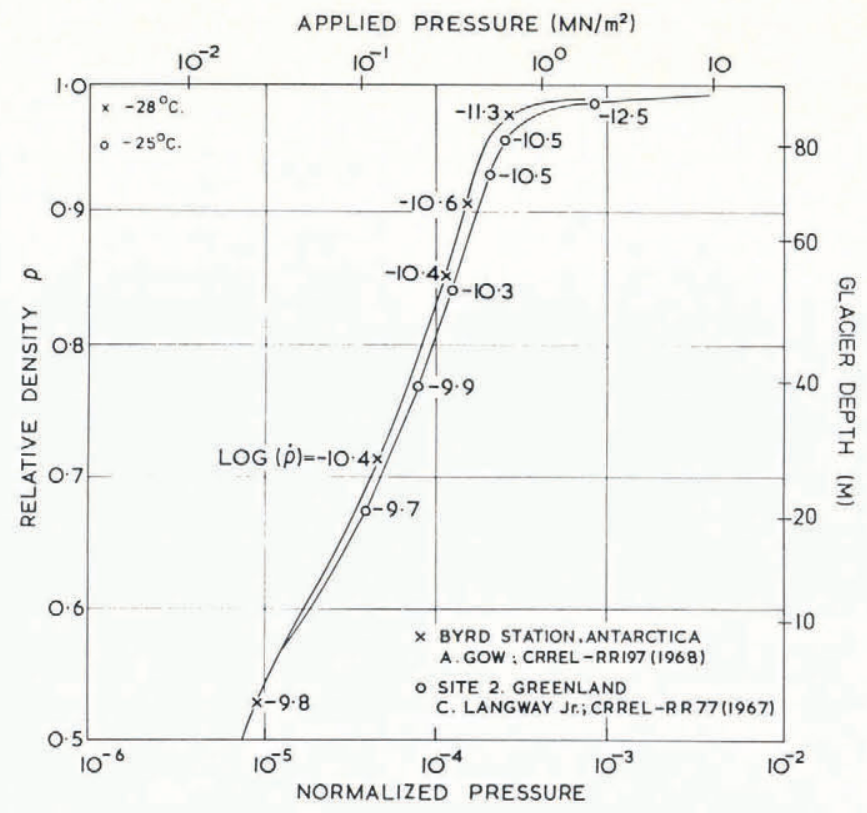

Fig. 5. The pressure-density contour for two polar ice sheets is plotted using the same axes as Figure 1. Measured densification rates $\left(\log _{10}\right)$ are also shown.

densification-rate contours. They lie entirely within the power-law creep field up to about $98 \%$ density. Although the map cannot show sufficient detail, further analysis shows that above $98 \%$ density the gas pressure rises rapidly and the driving pressure is lowered, resulting in latticediffusion control thereafter. The fit between data and map is tolerable considering the nature and scatter of the data and the fact that the creep data are drawn from tests on laboratory and not glacier ice.

The theory can be compared with the observed data more closely by producing diagrams of densification rate as a function of depth or density, as in Figure 6. If the average rate of snow accumulation (mass of snow deposited per unit area per unit time) is known, then the age is related simply to depth by

$$
\mathrm{d} h=\frac{w}{\rho \Delta_{0}} \mathrm{~d} t
$$

where $h$ is the depth, $t$ the age, and $\rho$ the relative density of the ice. $\Delta_{0}$ is the theoretical density of ice at the icesheet temperature, and $w$ is that rate of snow accumulation. The increase of pressure is related to depth by

$$
\mathrm{d} p_{\mathrm{e}}=\rho g \mathrm{~d} h
$$

where $g$ is the acceleration due to gravity. The diagram which results from this analysis for Site 2, Greenland, using $w=410 \mathrm{~kg} \mathrm{~m}^{-2}$ year $^{-1}\left(1.3 \times 10^{-5} \mathrm{~kg} \mathrm{~m}^{-2} \mathrm{~s}^{-1}\right)$ and $R=1 \mathrm{~mm}$ is shown in Figure 6, in which the densification rate on a $\log$ scale is plotted against both depth and density. Since most of the density change occurs during the first $50 \mathrm{~m}$ or so, Figure $6 \mathrm{~b}$ is more useful for considering the low-density behaviour, while Figure $6 \mathrm{a}$ is more useful for determining the rate at which the final porosity is eliminated. Below about $95 \mathrm{~m}$ in depth the densification is controlled primarily by the internal gas pressure $\left(p_{\mathrm{i}}>0.9 p_{\mathrm{e}}\right)$. The ice sheet can only densify as fast as accumulating snow on the surface increases the load pressure $p_{\mathrm{e}}$. The dominant mechanism at these depths is lattice diffusion since, despite the increasing external pressure, the driving pressure $p\left(=p_{\mathrm{e}}-p_{\mathrm{i}}+2 \gamma_{\mathrm{S}} / r\right)$ is small and continuously falling. ${ }^{*}$

*As noted by Gow and Williamson (1975), gas bubbles begin to dissolve under pressure at about $700 \mathrm{~m}$ depth, which requires an adjustment to the analysis for very large depths. However, this is beyond the range of the present analysis. 

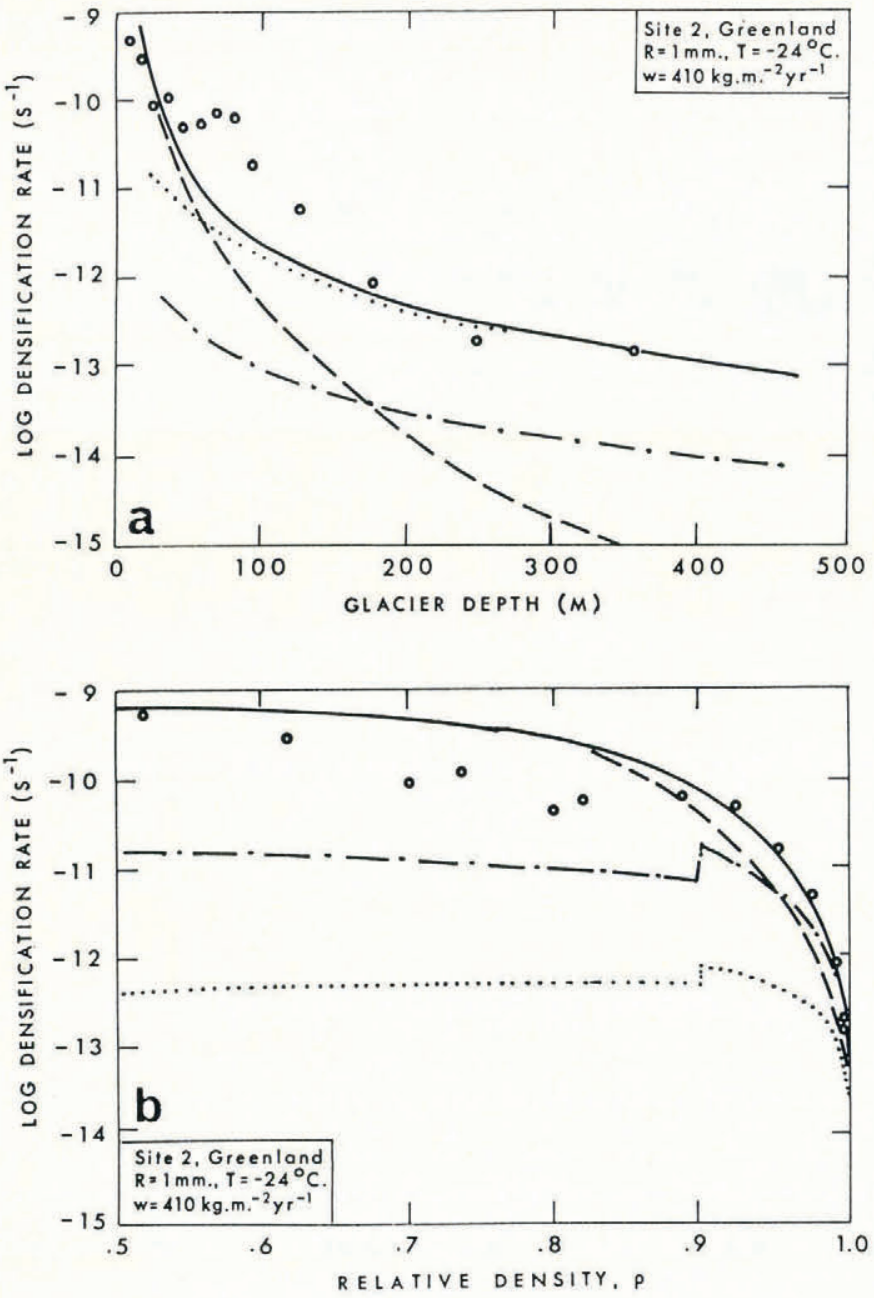

Fig. 6. Theoretical plots of densification rate versus (a) depth, and (b) density, with experimental data for comparison. The particle radius used is appropriate below about $80 \mathrm{~m}$ depth. The various lines represent predicted densification rates due to power-law creep (- - -), lattice diffusion (......), boundary diffusion (-.-.-.), and all mechanisms (--)). The circles represent measured densification rates.

The diagram shows good agreement between the theoretical and measured densification rates, especially at large depths where diffusion is controlling. At lower depths, the particle radius used is too large and the predicted densification rate in the $30-80 \mathrm{~m}$ regions should be higher by about a factor of 4 .

\section{DISCUSSION}

Diagrams such as those in Figure 6 can be produced for other polar ice sheets or glaciers or for different parts of the same ice sheet, even if no deep core has been drilled. The only information required is the ice temperature (below the depth of the seasonal oscillations), the average snow-accumulation rate, and the grain-size. Enough information is available at present to enable a reasonable estimate of grain-size as a function of time from a knowledge of the temperature. Furthermore, the power-law creep mechanism is independent of grain-size and so only a lower limit for grain-size is required when it dominates densification. The temperature and snowaccumulation rate can be found by drilling a relatively shallow core of about $20 \mathrm{~m}$ (Gow, 1968).

The analysis performed here assumes that the external driving force for densification of polar firn arises solely from the accumulated snow load. This may not always be the case. Glaciers or ice sheets, or parts thereof, may deform as they move. In this case, large deviatoric stresses can be induced which will also influence the rate of densification by the power-law creep mechanism. This has been illustrated recently by Alley and Koci (1988) using data from two different cores with the same temperature and snow-accumulation rates, but different levels of deviatoric applied stresses. An analysis of these effects is beyond the scope of this paper. The two sites studied here are both at about the same temperature and have similar accumulation rates, and are not subject to external forces other than snow load. They therefore show very similar behaviour.

Polar ice temperatures range from about $-15^{\circ} \mathrm{C}$ to about $-57^{\circ} \mathrm{C}$ (Vostok). There is evidence (see Table II) that the activation energy for power-law creep is larger than that for lattice diffusion, thus increasing the relative importance of lattice diffusion at low temperatures. Grain growth is slower at lower temperatures, and this also increases the relative importance of lattice diffusion. Thus, lattice diffusion may well control densification over most or all of the density range in very cold ice. Furthermore, while no data exist for grain-boundary diffusion, estimates based on data for metals (see Table II) suggest that it may make a contribution to densification in cold ice sheets, particularly when the porosity is very low. One must therefore be careful in extrapolating data to different conditions, but mechanism maps give an idea of the trends one can expect to see. In general, they show that power-law creep dominates the densification over a large range of density and this range is increased for higher temperatures and snow-accumulation rates. Mechanism maps produced for a range of temperatures would be useful for predicting whether this behaviour is altered for lower-temperature ice.

\section{CONCLUSIONS}

(i) Comparison of deep-core data from two polar ice sheets (Site 2, Greenland; and Byrd Station, Antarctica) with pressure-sintering theory shows that power-law creep controls densification between $50 \%$ and $98 \%$ theoretical density.

(ii) At low porosities, the driving force drops and lattice diffusion from grain boundaries to the pores becomes dominant.

(iii) The presence of air trapped in the pores (until large depths) causes a significant drop in the densification rate below that which one would expect if the pores were evacuated.

(iv) Pressure-sintering mechanism maps provide a useful way of analyzing the densification of polar ice, and of illustrating its behaviour.

(v) Data collected from a relatively shallow core (about $20 \mathrm{~m}$ in depth) may be used with the theory to estimate the densification behaviour of any polar glacier or ice sheet to several hundred metres depth.

\section{ACKNOWLEDGEMENTS}

It is with pleasure that I acknowledge the influence of Professor M.F. Ashby on this work, through many fruitful discussions. I have also benefited from discussions with $\mathrm{Dr}$ A.J. Gow and Dr R.B. Alley. This work is supported by a grant from the Natural Science and Engineering Research Council, Canada.

\section{REFERENCES}

Alley, R.B. 1987. Firn densification by grain-boundary sliding: a first model. Journal de Physique, 48, (Colloque $\mathrm{Cl}$, Supplément au No. 3), 249-56.

Alley, R.B., and Koci, B.R. 1988. Ice-core analysis at Site A, Greenland: preliminary results. Annals of Glaciology, $10,1-4$.

Anderson, D.L., and Benson, C.S. 1963. The densification and diagenesis of snow. In Kingery, W.D., ed. Ice and snow; properties, processes and application. Cambridge, MA, M.I.T. Press, 391-411. 
Barnes, P., Tabor, D., and Walker, J.C.F. 1971. The friction and creep of polycrystalline ice. Proceedings of the Royal Society of London, Ser. A, 324(1557), 127-55.

Coble, R.L. 1970. Diffusion models for hot pressing with surface energy and pressure effects as driving forces. Journal of Applied Physics, 41, 4798-807.

Coleman, S.C., and Beere, W. 1975. The sintering of open and closed porosity in $\mathrm{UO}_{2}$. Philosophical Magazine, 31, 1403-15.

Dantl, G. 1968. Die elastischen Moduln von Eis-Einkristallen. Physik der Kondensierten Materie, 7(5), 390-97.

Fletcher, N.H. 1970. The chemical physics of ice. Cambridge, Cambridge University Press.

Gow, A.J. 1968. Deep core studies of the accumulation and densification of snow at Byrd Station and Little America V, Antarctica. CRREL Research Report 197.

Gow, A.J. 1975. Time-temperature dependence of sintering in perennial isothermal snowpacks. International Association of Hydrological Sciences Publication 114
(Symposium of Grindelwald 1974 - Snow Mechanics), 25-41.

Gow, A.J., and Williamson, T. 1975. Gas inclusions in the Antarctic ice sheet and their glaciological significance. Journal of Geophysical Research, 80(36), 5101-08.

James, P.J. 1972. Powder Metallurgy International, 4, 1-10.

Langway, C.C., jr. 1967. Stratigraphic analysis of a deep ice core from Greenland. CRREL Research Report 77.

Ramseier, R.O. 1967. Self-diffusion of tritium in natural and synthetic ice monocrystals. Journal of Applied Physics, 38(6), 2553-56.

Swinkels, F.B., Wilkinson, D.S., Arzt, E., and Ashby, M.F. 1983. Mechanisms of hot isostatic pressing. Acta Metallurgica, 31, 1829-93.

Wilkinson, D.S. Unpublished. The mechanisms of pressure sintering. (Ph.D. thesis, University of Cambridge, 1978.)

Wilkinson, D.S., and Ashby, M.F. 1975. Pressure sintering of power-law creep. Acta Metallurgica, 23, 1277-85.

Wilkinson, D.S., and Ashby, M.F. 1978. Mechanism mapping of sintering under an applied pressure. Scientific Sintering, 10, 67-76. 